malignancies (six in 1989 and 20 in 1990) and that many of these are not suspected to be malignant before excision. Controversy exists about whether general practitioners should remove malignant lesions. Paver suggests that if the diagnosis is uncertain, there is a facial lesion, or malignant melanoma is suspected the patient should be referred to a consultant. ${ }^{1}$ However, if there are long waiting times for consultant appointments there is strong argument for family doctors doing the surgery as early excision of skin malignancy is more likely to cure.
Whether removing malignant lesions or not it is imperative that general practitioners who wish to undertake minor surgery are adequately trained and that all biopsy specimens are submitted for histological examination.

1 Paver RD. Practical procedures in dermatology. Aust Fam Physician 1990;19: 699-701.

2 Brundel KH. Skin cancer in general practice. Dermatosen in Beruf und Unwelt 1990;38:54-7.

(Accepted 28 August 1991

\section{Effect of general practitioner contract on referral of specimens for histological examination}

\section{K J Hillan, C P Johnson, R Morton}

Department of Pathology, Southern General Hospital, Glasgow G51 4TF

K J Hillan, FRCs, registrar $\mathrm{C} P$ Johnson, $\mathrm{MB}$, registrar R Morton, FRCPATH, consultant

Correspondence to: Mr Hillan.

BMศ 1991;303:1180 resources to be spent on more urgent needs.

We reviewed all surgical specimens sent for histological examination over the four years April 1987-91 to assess the impact of the new contract. The speci-
Increasing criticism has been voiced in recent years over the time patients spend waiting for minor surgery. ${ }^{12}$ To reduce pressure on hospital waiting lists general practitioners are now paid for such surgery as part of their new contract. General practitioner surgery is preferred by patients, and it allows hospital mens received during April 1990-1 were compared with those sent from the hospital's surgical day theatre.

\section{Methods and results}

For each specimen we assessed the adequacy of the clinical information, including age and sex of patient, site of lesion, duration of lesion, method of fixation, and completeness of excision.

We received 149 specimens from general practitioners during April 1987-91; 121 (81\%) were sent during April 1990-1 (table), with none, 21, and 7 in the

Comparison of specimens received from general practitioners and surgical day theatre, April 1990-1. Number of malignant lesions not completely excised given in parentheses

\begin{tabular}{lcc}
\hline & $\begin{array}{c}\text { General } \\
\text { practitioner }\end{array}$ & $\begin{array}{c}\text { Surgical } \\
\text { day theatre }\end{array}$ \\
\hline Benign lesions: & & \\
Simple papilloma & 37 & 31 \\
Cyst & 21 & 11 \\
Naevus & 15 & 14 \\
Skin tag & 10 & 4 \\
Dermatofibroma or neurofibroma & 10 & 7 \\
Lipoma & 5 & 3 \\
Vascular & 5 & 4 \\
Inflammatory & 4 & 15 \\
Sweat gland tumour & 1 & 4 \\
Others & 8 & 4 \\
Malignant lesions: & & $1(1)$ \\
Actinic keratosis & $1(1)$ & $3(1)$ \\
Bowen's disease & & $1(1)$ \\
Intraduct carcinoma (male breast) & $3(2)$ & $3(0)$ \\
Basal cell carcinoma & $1(0)$ & $1(1)$ \\
Secondary carcinoma & 121 & 106 \\
Melanoma & & \\
\hline Total & & \\
\hline
\end{tabular}

three preceding years. The female to male ratio of the patients was $1: 1$ and the average age was 51.5 (range 12-90) years. Twenty two general practitioners sent specimens; $72(59 \%)$ specimens were from four practitioners, and $49(40 \%)$ were from one practice.

Of the 121 specimens received during April 1990-1, $19(16 \%)$ were in the wrong fixative. The duration of the lesion was given in only $18(15 \%)$ cases. Excluding this, clinical information was complete in $102(67 \%)$ cases. Twelve $(10 \%)$ specimens were incompletely excised. During April 1990-1, we received 106 specimens from the surgical day theatre, from 343 excisions (31\%) (table). The female to male ratio of the patients was $3: 2$ and the average age was $50 \cdot 2$ (range 17-93) years. All specimens were in the correct fixative, but the duration of the lesion was given on only $10(12 \%)$ referral forms. Excluding this, clinical details were adequate in $99(94 \%)$ cases. Twelve $(11 \%)$ lesions were inadequately excised

\section{Comment}

The number of specimens referred to our department from general practitioners has increased considerably since the introduction of the new contract in April 1990. The specimens referred from general practitioners were similar to those received from the surgical day theatre and the groups were matched for age and sex.

At this hospital waiting times for non-urgent surgical appointments range from one to two weeks and minor operations are generally carried out within one week after attending the clinic. In areas with longer waiting lists a greater increase in referrals from general practitioners is likely.

Despite previous concerns ${ }^{4}$ we found little evidence that unnecessary operations were being performed. Furthermore, the rates of misdiagnosis of malignant lesions and incomplete excision were similar among patients treated by general practitioners and those treated in hospital. Nevertheless, with more general practitioners performing minor operations, many of whom are removing only-a few lesions a year, the need for histological examination in all cases cannot be overstated.

I Brown JS. Minor operations in general practice. BMF 1979;i:1609-10.

2 Wall DW. A review of minor surgery in general practice in the United Kingdom. Fam Pract 1987:4:322-9.

Coopers and Lybrand Associates. The cost effectiveness of general practice.

London: British Medical Association, 1983. (General Medical Services Committee discussion document.)

4 Milne R. Minor surgery in general practice. Br $\mathcal{F}$ Gen Pract 1990;40:175-6.

(Accepted 28 August 1991 ) 